\title{
o CuIdAdo de enfermagem e A INVASÃo da PRIVACIDAde do doENTE: UMA QUESTAO ÉTICO-MORAL'1
}

\author{
Jussara Simone Lenzi Pupulim ${ }^{2}$ \\ Namie Okino Sawada ${ }^{3}$
}

Pupulim JSL, Sawada NO. O cuidado de enfermagem e a invasão da privacidade do doente: um questão ético-moral. Rev Latino-am Enfermagem 2002 maio-junho; 10(3):433-8.

Os enfermeiros constantemente invadem a intimidade e a privacidade do doente ao realizar os cuidados de enfermagem, porém raramente discutem os aspectos que envolvem esse problema. A literatura de enfermagem abrangendo esse tema é escassa, motivando a elaboração deste estudo com o objetivo de sensibilizar os enfermeiros quanto à relevância e necessidade de reflexão sobre o assunto. Ressaltam-se questões ético-legais e morais que permeiam a invasão da privacidade, apontando as responsabilidades dos profissionais de enfermagem. Discute-se a atuação dos Comitês de Ética em Pesquisa e das Comissões de Ética de Enfermagem das Entidades como mecanismos de controle e proteção dos indivíduos, circunstanciando, principalmente, a respeito da conduta e postura dos enfermeiros no processo de cuidar. O estudo alerta para a necessidade de discussão e reavaliação dos papéis desses mecanismos e da qualidade da assistência de enfermagem, uma vez que a proteção da privacidade dos doentes ainda é deficiente.

DESCRITORES: privacidade, cuidados de enfermagem, ética de enfermagem

\section{NURSING CARE AND THE INVASION OF PATIENTS' PRIVACY: AN ETHICAL AND MORAL ISSUE}

Nurses constantly invade patients' intimacy and privacy when delivering nursing care; however, they rarely discuss the aspects involving such issue. Nursing literature on this theme is scarce, which has motivated the development of this study with the purpose to sensitize nurses as to the relevance of and need for reflection on this matter. Ethical, legal and moral questions that permeate the invasion of privacy are pointed out, thus showing the responsibilities of nursing professionals. The actions of Committees of Ethics in Research as well as those of Nursing Ethics Committees in Organizations are discussed as mechanisms for the control and protection of individuals, mainly approaching the conduct and attitudes of nurses in the care-giving process. This study emphasizes the need for discussions and reevaluations of the roles of such mechanisms and of the quality in nursing care, since protection to patients' privacy is still deficient.

DESCRIPTORS: privacy, nursing care, nursing ethics

\footnotetext{
${ }^{1}$ Trabalho apresentado na disciplina de pós-graduação "Ética em pesquisa envolvendo seres humanos" oferecida pela Faculdade de Filosofia, Ciências e Letras de Ribeirão Preto, da Universidade de São Paulo; ${ }^{2}$ Professor Auxiliar do Departamento de Enfermagem da Universidade Estadual de Maringá, Mestranda do Programa de Enfermagem Fundamental, e-mail: jslpupulim@bol.com.br; ${ }^{3}$ Professor Doutor, e-mail: sawada@eerp.usp.br. Escola de Enfermagem de Ribeirão Preto, da Universidade de São Paulo, Centro Colaborador da OMS para o desenvolvimento da pesquisa em enfermagem
} 


\section{EL CUIDAdO de ENFERMERÍA Y LA INVASIÓN DE LA PRIVACIDAd DEL ENFERMO: UNA CUESTIÓN ÉTICO-MORAL}

Los enfermeros constantemente invaden la intimidad y la privacidad del enfermo al realizar los cuidados de enfermería, raramente discuten los aspectos que involucran este problema. La literatura de enfermería sobre el tema es escasa, motivando la elaboración de este estudio con el objetivo de sensibilizar los enfermeros al respecto de la relevancia y necesidad de reflexión sobre el asunto. Son resaltadas las cuestiones ético-legales y morales involucradas en la invasión de la privacidad, apuntando las responsabilidades de los profesionales de enfermería. Se discute la actuación de los Comités de Ética en Investigación y de las Comisiones de Ética de Enfermería de las entidades como mecanismos de control y protección de los individuos, circunscribiendo la conducta y postura de los enfermeros en el proceso de cuidar. El estudio alerta para la necesidad de discusión y re-evaluación de los papeles de estos mecanismos y de la calidad de la atención de enfermería, una vez que la protección de la privacidad de enfermos todavía es deficiente.

DESCRIPTORES: privacidad, cuidados de enfermería, ética de enfermería

\section{INTRODUÇÃO}

$\boldsymbol{A}$ condição de enfermidade gera sentimentos como incapacidade, dependência, insegurança e sensação de perda do controle sobre si mesmo. Os doentes encaram a hospitalização como fator de despersonalização por reconhecerem a dificuldade para manter sua identidade, intimidade e privacidade. $O$ ambiente hospitalar é estressante por diversos fatores, essencialmente ao doente, por perder o controle sobre os que o afetam, e dos quais depende para a sua sobrevivência. Além disso, a internação é angustiante por evidenciar a fragilidade a que estão sujeitos, devido à exposição emocional e física.

A enfermagem não pode ignorar que, ao cuidar do doente, toca-lhe o corpo e o expõe, muitas vezes sem pedir autorização, adotando uma postura de "poder" sobre o corpo de outrem. O doente pouco questiona essa invasão porque, na sua percepção, ela é necessária para sua recuperação, porém demonstra constrangimento, vergonha e embaraço.

Um estudo que discute as relações sociais e de poder no contexto hospitalar sugere que a submissão do doente à enfermagem e a outros profissionais da área da saúde ocorre por entender que o "saber" dessas profissões Ihes confere o direito de manipular seu corpo ${ }^{(1)}$.

Outra investigação constatou que pacientes internados em Unidade de Terapia Intensiva (UTI) "que sobrevivem, sabem que uma jornada na UTI só não é pior que a morte e que todos os pudores da vida em sociedade se esvanecem, pois homens e mulheres expõem seus corpos, que são manuseados pelos enfermeiros"(2). Contudo, o enfermeiro "é o profissional da área de saúde que tem maior autorização social para tocar o corpo do

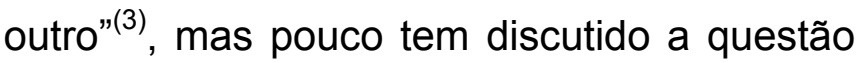
da nudez, que é um fator a mais de estresse e sofrimento para o paciente, dificultando sua adaptação ao ambiente hospitalar ${ }^{(4)}$.

Para um indivíduo, mesmo doente, estar despido pode significar desconforto e embaraço. Afinal, culturalmente e no núcleo familiar, aprende-se que expor o corpo não é apropriado, relacionando-se implicitamente a nudez com sensualidade e sexualidade, comuns aos indivíduos, mas, de certa forma, reprimidas, de acordo com os padrões de comportamento vigentes na sociedade. 


\section{FUNDAMENTOS TEÓRICOS}

A invasão do território e do espaço pessoal fere a dignidade do indivíduo. A privacidade é uma necessidade e um direito do ser humano, sendo indispensável para a manutenção da sua individualidade ${ }^{(5-6)}$. No entanto, é importante ressaltar que o Capítulo IV - DOS DEVERES do Código de Ética dos Profissionais de Enfermagem ${ }^{(7)}$, preconiza que o enfermeiro deve: "Art. 27- Respeitar e reconhecer o direito do cliente de decidir sobre sua pessoa, seu tratamento e seu bem estar. Art. 28- Respeitar o natural pudor, privacidade e a intimidade do cliente". Ao mesmo tempo, o enfermeiro tem que reconhecer que o paciente possui: "o direito a atendimento humano, atencioso e respeitoso, por parte de todos os profissionais de saúde. Tem o direito a um local digno e adequado para seu atendimento, o direito a manter sua privacidade para satisfazer suas necessidades fisiológicas, inclusive alimentação e higiênicas, quer quando atendido no leito, no ambiente onde está internado ou aguardando atendimento"(8).

Sendo o enfermeiro o profissional em constante contato com o doente durante a hospitalização, é imprescindível circunstanciar sobre a conduta da enfermagem no sentido de resguardar esses direitos. A enfermagem procura preservar a intimidade e a privacidade dos doentes usando biombos, cobrindo partes do corpo que não precisam ficar expostas durante um procedimento e solicitando que familiares/visitas retirem-se do quarto/ enfermaria ao realizar um cuidado, caracterizando essa tentativa de proteção como um gesto humanitário e de respeito.

Essa ação pode representar uma atitude de defesa à fragilidade pela doença, resgatando o instinto maternal, sentimento forte nesses profissionais, ou simplesmente uma atitude que facilitará a assistência de enfermagem, dificultando a intervenção ou questionamento dos familiares.

Em algumas situações, a enfermagem invariavelmente invadirá a privacidade e a intimidade do doente, como na passagem de cateter vesical, banho no leito, enemas e outros. Entretanto, o doente, sujeito do processo de trabalho da enfermagem, é um ser humano e, como tal, tem personalidade, dignidade, honra, pudor e preconceito. Para que haja interação entre enfermeiro e paciente, é importante conhecer a sua natureza física, cultural, espiritual, social e psicológica. Esses aspectos são significativos ao se tentar estabelecer uma relação de confiança junto ao doente, no sentido de transmitir segurança e apoio. Atitudes de respeito à individualidade, humildade, tolerância, tranqüilidade e solidariedade podem minimizar o estresse pela doença e internação. Todos estes fatores são importantes, mas será que são suficientes para proteger a identidade, a privacidade e a intimidade do doente?

O direito a um espaço como pessoa, sob o aspecto legal, é propriedade inatingível de todo cidadão. $\mathrm{O}$ Art. $5^{\circ}$, parágrafo $X$ da Constituição da República Federativa do Brasil $^{(9)}$, de 1988, prevê que: "são invioláveis a intimidade, a vida privada, a honra e a imagem das pessoas, assegurando o direito à indenização pelo dano material ou moral decorrente de sua violação". Em resposta aos anseios e inquietações da população, a Organização das Nações Unidas (ONU) promulgou, em 1948, a Declaração Universal dos Direitos Humanos ${ }^{(10)}$, assegurando, no "Art. $12^{\circ}$ Ninguém sofrerá intromissões arbitrárias na 
sua vida privada, na sua família, no seu domicílio ou na sua correspondência, nem ataques à sua honra e reputação. Contra tais intromissões ou ataques toda pessoa tem direito à proteção da lei".

As comunidades política e científica também têm se preocupado com a proteção dos indivíduos, desenvolvendo mecanismos de controle, como o Código de Nuremberg (1947), a Declaração de Helsinque (1964), e, no Brasil, isso se efetivou com a formulação da Resolução 196/96, pelo Conselho Nacional de Saúde (1996). Eles priorizam as pesquisas científicas que envolvem seres humanos, uma vez que a racionalidade científica encobre o valor da subjetividade na produção do conhecimento, evidenciando-se a necessidade de harmonizar objetividade, razão, subjetividade e humanização.

Foram criados, então, os Comitês de Ética em Pesquisa (CEP) e as Comissões de Ética nos Hospitais. Os primeiros, com a finalidade de orientar, instruir, analisar a validade das pesquisas e deliberar sobre assuntos éticos pertinentes aos protocolos, além de "receber e apurar denúncias e determinar a interrupção de projetos de pesquisa quando necessário"(11). Os últimos, com a função de analisar, interpretar e adequar as atividades dos profissionais, diante de valores éticos, direitos, deveres, à legislação de cada categoria profissional.

No caso dos enfermeiros, a Comissão de Ética de Enfermagem das Entidades tem o propósito educativo, opinativo, consultivo, fiscalizador e de assessorar em questões éticas do exercício da profissão, durante atuação na assistência, ensino, pesquisa e administração $^{(12)}$. Dentre as competências previstas para essa Comissão, conforme a
Decisão No 18 do COREN-SC, consta no Art. $12^{\circ}$, parágrafo $11^{(12)}$, que seus membros devem fiscalizar "a qualidade de atendimento dispensado à clientela pelos profissionais de enfermagem as condições oferecidas pela entidade e sua compatibilidade com o desempenho ético - profissional".

Os enfermeiros, ao interpretarem superficialmente essas competências, provavelmente compreendem apenas o que reporta ao tecnicismo da assistência de enfermagem, não levando em consideração os aspectos individuais e emocionais dos doentes quanto à preservação da sua intimidade, do seu espaço pessoal e territorial. Todavia, "saúde", para a Organização Mundial de Saúde (OMS), não é meramente a ausência de doença, mas também o completo bem-estar físico, psíquico e social do indivíduo, dimensionando este problema, mas que raramente é abordado, embora provoque muito "mal-estar" ao indivíduo enfermo.

\section{CONSIDERAÇÕES GERAIS}

Atualmente, tem se discutido muito o comportamento ético, moral e legal, referindose a questões políticas, conflitos religiosos, influência do avanço tecnológico e das pesquisas científicas. Se ética é a ciência da moral, implicando juízo de valores, e moral refere-se a conduta/comportamento do ser humano, não seria a invasão da privacidade do doente, durante o cuidado de enfermagem, uma questão ética a ser encarada com mais seriedade e importância por esses profissionais?

Outras questões também emergem para discussão e reflexão por parte dos enfermeiros, 
tais como: que percepção os enfermeiros têm sobre o que ocorre com o doente durante os cuidados? O quê e como os enfermeiros fazem para proteger os doentes? Como eles interpretam e compreendem as competências das Comissões de Ética de Enfermagem e de seus membros no âmbito hospitalar, e também os Artigos 27 e 28 do Código de Ética dos Profissionais de Enfermagem? Conhecem os direitos dos doentes? Não seria mais importante ajudá-los a trabalhar com a perda da privacidade do que simplesmente preservar o seu espaço pessoal?

Ao se levantarem esses questionamentos, procura-se sensibilizar prioritariamente os profissionais de enfermagem, como também os das demais áreas da saúde, quanto à garantia que os indivíduos têm de que sua privacidade e individualidade será resguardada, tanto na condição de doente quanto na situação de sujeitos de uma pesquisa científica.

$\mathrm{O}$ avanço foi significativo em relação às pesquisas envolvendo seres humanos, após a promulgação da Resolução 196/96. Os CEPs empenham-se em analisar rigorosamente esses projetos, com atenção especial ao Termo de Consentimento Livre e Esclarecido, porém raramente acompanham o desenvolvimento das investigações e a conduta do pesquisador, exceto em caso de denúncia. $E$ as Comissões de Ética Hospitalar geralmente só se reúnem para apurar questões ético-legais

\section{REFERÊNCIAS BIBLIOGRÁFICAS}

1. Carapinheiro G. Saberes e Poderes no Hospital: uma sociologia dos serviços hospitalares. Porto: Afrontamento; 1993.

2. Pastore K. Uma jornada no inferno. Veja 1995 maio; 28(19):72-9. encaminhadas para análise e apreciação, não supervisionando nem fiscalizando a conduta e postura dos profissionais.

O "homem" vem absorvendo informações em quantidade, qualidade e rapidez, possibilitadas pelo progresso tecnológico e científico, tornando-o mais exigente quanto aos seus direitos. É necessário discutir e reavaliar o papel dos Comitês e Comissões, enquanto mecanismos de controle e proteção dos indivíduos.

São poucos os trabalhos que discorrem sobre a questão da privacidade do doente no contexto da enfermagem, no entanto já se alerta sobre a relevância desse tema como sendo "um conceito chave em enfermagem"(13), principalmente quando relacionado à qualidade da assistência, uma vez que os enfermeiros ainda apresentam falhas na proteção dos pacientes.

A enfermagem muito tem se desenvolvido no processo de cuidar, acreditando que é a arte e a ciência de cuidar, ou seja, "é gente que cuida de gente" ${ }^{(14)}$. Na verdade, cuidar é muito mais que um ato, é uma atitude de "ocupação, preocupação, de responsabilização e de envolvimento afetivo com o outro"(15), exigindo compromisso dos profissionais enfermeiros para com o semelhante. A enfermagem não pode nem deve dimensionar só a doença, mas o indivíduo como um todo, o qual, por estar doente, precisa de cuidado pessoal e especial.

3. Miranda CML. O parentesco imaginário. São Paulo (SP): Cortez; 1994.

4. Silveira MFA. Estar despido na UTI: duas percepções, um encontro. Rev Enfermagem UERJ 1997 dezembro; 5(2):449-59.

5. Sawada NO. O sentimento do paciente hospitalizado frente à invasão de seu espaço territorial e pessoal. [tese]. Ribeirão Preto (SP): Escola de Enfermagem de Ribeirão Preto/USP; 1995. 
6. Sawada NO, Galvão CM, Mendes IAC, Dela Coleta JA. Invasão do território e espaço pessoal do paciente hospitalizado: adaptação de instrumento de medida para a cultura brasileira. Rev Latino-am Enfermagem 1998 janeiro; 6(1):5-10.

7. Conselho Federal de Enfermagem (RJ). Código de ética dos profissionais de enfermagem. Rio de Janeiro (RJ); 1993.

8. Gauderer EC. Os direitos do paciente: cidadania na saúde. $7^{\text {a }}$ ed. Rio de Janeiro (RJ): Record; 1998.

9. Senado Federal (BR). Constituição da República Federativa do Brasil. Brasília (DF): Centro Gráfico; 1998. 10. Declaração Universal dos Direitos Humanos. [citado em 30 de maio de 2001]: Disponível em: URL: http:// www.boes.org/un/porhr-b.html.

11. Oliveira MLC. Comitês de ética: pesquisa em seres humanos no Brasil. Rev Bras Enfermagem 1999 abr/jun; 52(2):189-94.

12. Gelain I, Mendes NTC, Silva MA. As comissões de ética nos hospitais: Seus problemas e sua operatividade. Anais do I Seminário Internacional de Filosofia e Saúde - A saúde como desafio ético; 1995 novembro 43-53; Florianópolis (SC): Sociedade de Estudos em Filosofia e Saúde; 1995.

13. Glen S, Jowlnally S. Privacidade: um conceito chave em enfermagem.. Nursing 1995 novembro; 8(94):35-8. 14. Horta WA. Processo de enfermagem. São Paulo (SP): EPU; 1995.

15. Boff L. Saber cuidar: ética do humano - compaixão pela terra. Petrópolis (RJ): Vozes; 1999. 